\title{
Do the World Cup Teams Perform Super-Efficiency?
}

\author{
Fazıl Gökgöz and Engin Yalçın
}

\begin{abstract}
It is significant to measure the efficiency of football teams so that sport efficiency analyses have increasingly become popular for professionals. Data Envelopment Analysis (DEA) technique has been implemented to numerous areas particularly football. Super-efficiency DEA method enables to discriminate among efficient decision-making units. This paper aims at employing CCR super-efficiency method to discriminate efficiency levels of national football teams participating in for the periods of World Cup 2014 and 2018. In this paper, accurate pass percentage, attempts on target and possession percentage have selected as input variables while the output variable has considered as goals scored through the tournaments. According to result of analyses, three teams have found efficient in $\mathbf{2 0 1 4}$ World Cup. Titleholder Germany is the most efficient team for super-efficiency CCR model. Besides, four teams have found as efficient for 2018 World Cup. Russia is found as the most efficient football team as per to the super-efficiency model in 2018. In further, titleholder France have shown high efficiency for 2018. The champion teams namely Germany and France have demonstrated full efficiency for both 2014 and 2018. Based on super-efficiency results, well performing teams demonstrate high efficiencies when compared to other teams. In this regard, we can conclude that super-efficiency DEA model can provide significant results in analyzing the football team both for official and individual decision makers.
\end{abstract}

Keywords - Football, Super-efficiency, Teams, World Cup.

\section{INTRODUCTION}

Football is a significant sport branch for most of the people. The football has a remarkable impact on world economy. Moreover, it is a field with intense competition.

Data Envelopment Analysis (DEA) is a non-parametric efficiency method depending on measuring relative efficiency of decision making units (DMUs) that have various inputs and outputs. The concept of DEA was initially presented by [3] [6].

Measuring performance of DMUs is significant because of some reasons [12]:

- If you could not measure outcomes, you could not elicit the performance properly.

- If you could not detect achievement, you could not reward it.

- If you could not reward success, you are likely to reward insufficient one.

Fazıl Gökgöz, Professor, Ankara University, Faculty of Political Sciences, Ankara-Turkey.

Engin Yalçın, Ph.D Student, Ankara University, Faculty of Political Sciences, Ankara-Turkey.
- If you could not detect disability, you could not make better the situation.

The aim of this study is to analyze the super-efficiency level of national teams participating in 2014 and 2018 World Cup. In this respect, we apply super-efficiency CCR model to evaluate the efficiencies of national teams. The principal contribution of this study is to analyze the super-efficiency levels of the World Cup teams.

The rest of the study has established as follows; part two shortly gives information about World Cup and its history and part three presents the super-efficiency DEA model. Part four illustrates empirical results; lastly, part five provides the concluding interpretations regarding outcomes.

\section{LITERATURE REVIEW}

Academic attention in professional team efficiency dates back as far as 1950s. The efficiency of football teams have already been analyzed in the literature. Reference [10] uses DEA game method to measure efficiency of Brazilian football teams. Reference [14] introduces a new approach called network DEA to evaluate the scoring efficiency of football teams in a match at Spanish league. Reference [8] utilizes DEA and ordered weighted averaging operators to evaluate players. Reference [5] employed multi-stage DEA to 2010 World Cup.

There are many papers carried out by super-efficiency model. Some of them are as follows: Reference [7] employ super-efficiency model to discern among efficient mutual funds. Reference [16] tries to analyze provincial efficiency by super-efficiency model. Reference [19] utilize super-efficiency model to analyze banking sector in Slovakia.

\section{BRIEF INFORMATION ABOUT THE WORLD CUP}

First World Cup was organized in 1930 in Uruguay [13]. Uruguay was the first nation winning the inaugural tournament. World Cup tournament was not held between 1938 and 1950 because of World War II. Uruguay beat Brazil in the final at Maracanã Stadium which had the highest ever attendance to a football match.

Brazil is the most successful nation in world football having won the World Cup 5 times [15]. Last World Cup was organized in Russia in 2018. Through this cup, totally 169 goals were scored, 2.6 average goals per match were scored as well. France won its second title in 2018 World Cup. 
World Cup titles for 1930-2018 period is illustrated in Figure 1 [20].

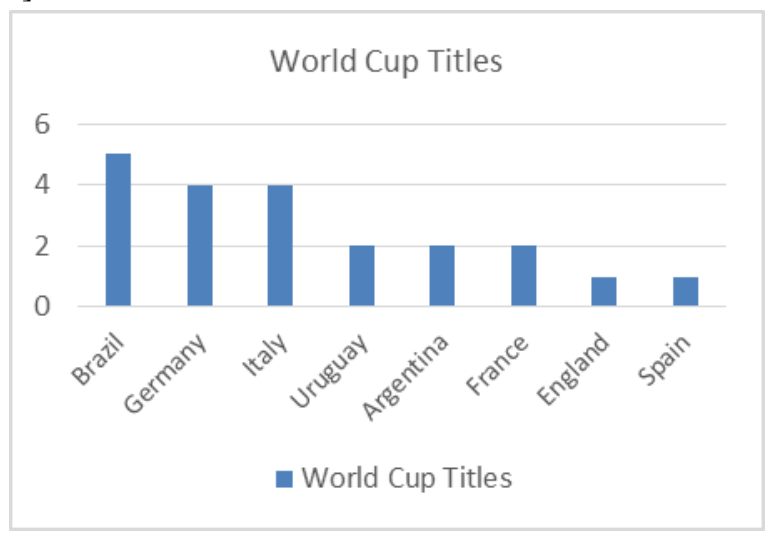

Fig. 1. World Cup titles

As shown in the figure, Brazil, Germany and Italy are the pioneers in the world cup tournaments.

\section{Methodology}

Data Envelopment Analysis (DEA) is a comparative linear programming method to measure relative performance of decision making units. DEA method tries to evaluate how efficiently a DMU utilizes available resources to produce outputs [9]. DEA was firstly used by [3]. Their formulation assumed constant returns to scale. Their method enabled various input and outputs. Reference [2] extended the model assuming variable returns to scale [11]. Since then, there have been numerous studies applied to many different performance evaluation areas by DEA method.

Super-efficiency DEA model was proposed by [1] Reference [1] used CCR super-efficiency to rank efficient units. Conventional CCR DEA model can not discern between decision making units when they are on the production frontier simultaneously [4]. Super-efficiency model bases on a reference technology set from other DMUs. Super-efficiency DEA model has shown in Table I [18].

TABLE I: SUPER-EFFICIENCY MODELS

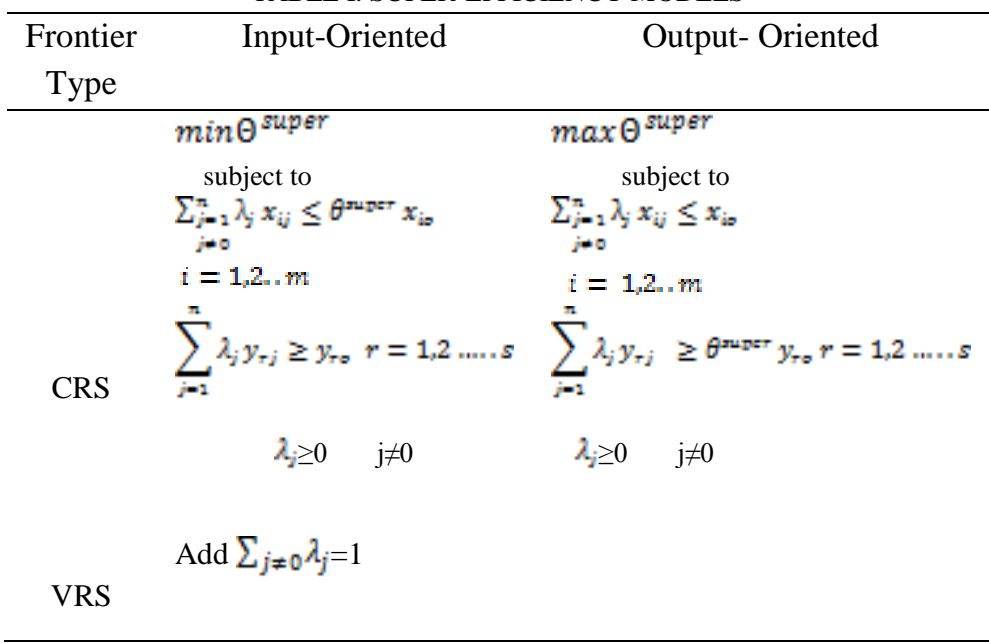

\section{EMPIRICAL RESULTS}

We measure super-efficiency level for national teams participating in 2014 and 2018 World Cup. Selecting the proper inputs and outputs has a remarkable importance in DEA process. Therefore, we determine the suitable inputs and outputs taking into consideration available papers. In this paper, accurate pass percentage, attempts on target, possession percentage are selected as inputs while scored goals are selected as output. We provide data from [21] and [22].

We apply input oriented CCR super-efficiency model to teams taking part in 2014 and 2018 World Cup. Table II and illustrates super-efficiency result for 2014 World Cup. TABLE II: SUPER-EFFICIENCY RESULT FOR TEAMS INVOLVED IN 2014 WORLD CUP

\begin{tabular}{ccc}
\hline DMUs & CCR & $\begin{array}{c}\text { Super- } \\
\text { Efficiency CCR }\end{array}$ \\
\hline Model & \\
\hline Netherlands & $96.36 \%$ & $96.36 \%$ \\
Colombia & $100.00 \%$ & $113.04 \%$ \\
Brazil & $66.91 \%$ & $66.91 \%$ \\
France & $64.14 \%$ & $64.14 \%$ \\
Argentina & $49.12 \%$ & $49.12 \%$ \\
Algeria & $100.00 \%$ & $100.76 \%$ \\
Switzerland & $55.86 \%$ & $55.86 \%$ \\
Croatia & $81.99 \%$ & $81.99 \%$ \\
Chile & $99.25 \%$ & $99.25 \%$ \\
Belgium & $38.55 \%$ & $38.55 \%$ \\
Mexico & $71.43 \%$ & $71.43 \%$ \\
USA & $58.34 \%$ & $58.34 \%$ \\
Cortugal & $44.98 \%$ & $44.98 \%$ \\
\hline Bosnia & $87.30 \%$ & $87.30 \%$ \\
Cote de Ivory & $42.02 \%$ & $42.02 \%$ \\
Ghana & $52.64 \%$ & $52.64 \%$ \\
\hline Spain & $54.66 \%$ & $54.66 \%$ \\
\hline
\end{tabular}




\begin{tabular}{|c|c|c|}
\hline \multirow[t]{2}{*}{ DMUs } & CCR & \multirow[t]{2}{*}{$\begin{array}{c}\text { Super- } \\
\text { Efficiency CCR }\end{array}$} \\
\hline & Model & \\
\hline Uruguay & $43.55 \%$ & $43.55 \%$ \\
\hline Ecuador & $52.38 \%$ & $52.38 \%$ \\
\hline South Korea & $39.29 \%$ & $39.29 \%$ \\
\hline Australia & $67.35 \%$ & $67.35 \%$ \\
\hline Greece & $31.55 \%$ & $31.55 \%$ \\
\hline Nigeria & $29.60 \%$ & $29.60 \%$ \\
\hline Italy & $39.29 \%$ & $39.29 \%$ \\
\hline Russia & $27.33 \%$ & $27.33 \%$ \\
\hline England & $33.08 \%$ & $33.08 \%$ \\
\hline Japan & $22.49 \%$ & $22.49 \%$ \\
\hline Iran & $26.19 \%$ & $26.19 \%$ \\
\hline Honduras & $18.49 \%$ & $18.49 \%$ \\
\hline Cameroon & $18.49 \%$ & $18.49 \%$ \\
\hline
\end{tabular}

Super-efficiency analysis results reveal that three teams are efficient. These teams are titleholder Germany, Colombia and Algeria. Titleholder Germany is the most efficient team for super-efficiency model. Table III reveals the super-efficiency results for 2018 World Cup teams.

TABLE III: SUPER-EFFICIENCY RESULT FOR TEAMS INVOLVED IN

\begin{tabular}{ccc}
\multicolumn{3}{c}{2018 WORLD CUP } \\
\hline DMUs & CCR & $\begin{array}{c}\text { Super- } \\
\text { Mfficiency CCR }\end{array}$ \\
\hline Croatia & $100.00 \%$ & $101.44 \%$ \\
Belgium & $100.00 \%$ & $108.80 \%$ \\
Brazil & $50.12 \%$ & $50.12 \%$ \\
England & $87.92 \%$ & $87.92 \%$ \\
France & $100.00 \%$ & $100.12 \%$ \\
Spain & $57.58 \%$ & $57.58 \%$ \\
Germany & $17.27 \%$ & $17.27 \%$ \\
Uruguay & $56.09 \%$ & $56.09 \%$ \\
Mexico & $39.86 \%$ & $39.86 \%$ \\
Switzerland & $61.69 \%$ & $61.69 \%$
\end{tabular}

\begin{tabular}{|c|c|c|}
\hline DMUs & $\begin{array}{l}\text { CCR } \\
\text { Model }\end{array}$ & $\begin{array}{c}\text { Super- } \\
\text { Efficiency CCR }\end{array}$ \\
\hline Sweden & $52.37 \%$ & $52.37 \%$ \\
\hline Argentina & $57.58 \%$ & $57.58 \%$ \\
\hline Portugal & $74.03 \%$ & $74.03 \%$ \\
\hline Russia & $100.00 \%$ & $119.62 \%$ \\
\hline Japan & $64.77 \%$ & $64.77 \%$ \\
\hline Denmark & $43.18 \%$ & $43.18 \%$ \\
\hline Colombia & $86.36 \%$ & $86.36 \%$ \\
\hline Nigeria & $57.58 \%$ & $57.58 \%$ \\
\hline Tunisia & $66.43 \%$ & $66.43 \%$ \\
\hline Iceland & $28.79 \%$ & $28.79 \%$ \\
\hline Saudi Arabia & $34.55 \%$ & $34.55 \%$ \\
\hline Morocco & $34.55 \%$ & $34.55 \%$ \\
\hline $\begin{array}{c}\text { Korea } \\
\text { Republic }\end{array}$ & $47.11 \%$ & $47.11 \%$ \\
\hline Peru & $31.40 \%$ & $31.40 \%$ \\
\hline Australia & $43.18 \%$ & $43.18 \%$ \\
\hline Serbia & $49.35 \%$ & $49.35 \%$ \\
\hline Senegal & $57.58 \%$ & $57.58 \%$ \\
\hline Poland & $43.18 \%$ & $43.18 \%$ \\
\hline Egypt & $69.09 \%$ & $69.09 \%$ \\
\hline Costa Rica & $38.38 \%$ & $38.38 \%$ \\
\hline Panama & $43.18 \%$ & $43.18 \%$ \\
\hline Iran & $86.36 \%$ & $86.36 \%$ \\
\hline
\end{tabular}

Table III reveals that four teams are efficient for 2018 World Cup. These are Croatia, Russia, Belgium, and titleholder France. Russia is the most efficient team for super-efficiency model.

\section{CONCLUSIONS}

This study aims to analyze the efficiency level of World Cup teams by DEA super-efficiency method for 2014 and 2018 World Cup. In this respect, we employ input oriented CCR super-efficiency method. Conventional DEA method is unable 
to distinguish the efficient decision making units. Super-efficiency model can tackle with this deficiency of classical DEA model. The empirical study has revealed important conclusions for World Cup teams. In 2014 World Cup, 3 teams are efficient. These teams are Germany, Colombia and Algeria. Titleholder Germany is the most efficient team on the basis of super-efficiency model. Besides, in 2018 World Cup four teams are efficient. Russia is the most efficient team for super-efficiency model. Moreover, titleholder France demonstrates high efficiency. We may conclude that, well performing teams demonstrate high efficiencies when compared to other teams. Our empirical results are consistent with performance of World Cup teams on the pitch.

In this regard, we can conclude that super-efficiency DEA approach can provide significant conclusions to analyze efficiency level of football teams.

\section{REFERENCES}

[1] Andersen, P. and Petersen, N.C., (1993). "A Procedure for Ranking Efficient Units in Data Envelopment Analysis". Management Science vol.39, pp.1261-1264. https://doi.org/10.1287/mnsc.39.10.1261

[2] Banker, R. D., Charnes, A., and Cooper, W. W. (1984). "Some models for Estimating Technical and Scale Inefficiencies in Data Envelopment Analysis”. Management Science, vol.30 (9), pp.1078-1092. https://doi.org/10.1287/mnsc.30.9.1078

[3] Charnes, A., Cooper, W. W., and Rhodes, E. (1978). "Measuring the Efficiency of Decision Making Units". European Journal of Operational Research, 2(6), .429-444. https://doi.org/10.1016/0377-2217(78)90138-8

[4] Chen, N., Xu, L., and Chen, Z. (2017). "Environmental efficiency analysis of the Yangtze River Economic Zone using super efficiency data envelopment analysis (SEDEA) and tobit models". Energy, 134, 659-671.

https://doi.org/10.1016/j.energy.2017.06.076

[5] Djordjević, D. P., Vujošević, M., and Martić, M. (2015). "Measuring efficiency of football teams by multi-stage DEA model". Tehnicki Vjesnik, 22(3), 763-770. https://doi.org/10.17559/TV-20140306134047

[6] Kao, C., and Liu, S. T. (2014). "Multi-Period Efficiency Measurement in data Envelopment Analysis: The Case of Taiwanese Commercial Banks". Omega, Vol: 47, pp.90-98.

https://doi.org/10.1016/j.omega.2013.09.001

[7] Lin, R., and Li, Z. (2019). "Directional distance based diversification super-efficiency DEA models for mutual funds". Omega. https://doi.org/10.1016/j.omega.2018.05.009

[8] Oukil, A., and Govindaluri, S. M. (2017). "A systematic approach for ranking football players within an integrated DEA OWA framework". Managerial and Decision Economics, vol.38 (8), pp.1125-1136. https://doi.org/10.1002/mde.2851

[9] Ramanathan, R. (2003). "An introduction to data envelopment analysis: a tool for performance measurement." Sage.

[10] Roboredo, M. C., Aizemberg, L., and Meza, L. A. (2015). "The DEA Game Cross Efficiency Model Applied to the Brazilian Football Championship". Procedia Computer Science, 55, 758-763.ion, Vol: 11(15), pp.7515-7534. https://doi.org/10.1016/j.procs.2015.07.161

[11] Ruggiero, J. (2011). Frontiers in Major League Baseball, Sports Economics, Management and Policy, Springer. https://doi.org/10.1007/978-1-4419-0831-5

[12] Sport England Main Report (2001). "Performance Measurement for the Development of Sport" pp.1-78.
[13] Tomlinson, A., and Young, C. (2006). "National Identity and Global Sports Events: Culture, Politics, and Spectacle in the Olympics and the Football World Cup" Suny Press.

[14] Villa, G., and Lozano, S. (2016). "Assessing the Scoring Efficiency of a Football Match". European Journal of Operational Research, Vol.255 (2), pp.559-569. https://doi.org/10.1016/j.ejor.2016.05.024

[15] Wheelwright, W. (2014). "50 Quick Facts about World Cup", Andrews UK Limited.

[16] Yang, L., Ouyang, H., Fang, K., Ye, L., and Zhang, J. (2015). "Evaluation of regional environmental efficiencies in China based on Super-Efficiency-DEA”. Ecological Indicators, vol.51, pp.13-19. https://doi.org/10.1016/j.ecolind.2014.08.040

[17] Zambom-Ferraresi, F., García-Cebrián, L. I., Lera-López, F., and Iráizoz, B. (2017). "Performance Evaluation in the UEFA Champions League". Journal of Sports Economics, vol.18 (5), pp. 448-470. https://doi.org/10.1177/1527002515588135

[18] Zhu, J. (2014). Quantitative Models for Performance Evaluation and Benchmarking: Data Envelopment Analysis with Spreadsheets vol. 213 Springer.

[19] Zimková, E. (2014). "Technical efficiency and super-efficiency of the banking sector in Slovakia". Procedia Economics and Finance, vol.12, pp.780-787. https://doi.org/10.1016/S2212-5671(14)00405-5

[20] https://www.totalsportek.com/football/fifaworldcupwinners (Access Date: 17.10.2019)

[21] www.fifa.com FIFA official web site.(Access Date: 17.10.2019)

[22] www.whoscored.com whoscored Football Statistics.(Access Date: 17.10.2019) 